\title{
Detailed corneal and genetic characteristics of a pediatric patient with macular corneal dystrophy - case report
}

\author{
Anna Nowińska ${ }^{1,2^{*}}$,Edyta Chlasta-Twardzik ${ }^{1,2}$, Michał Dembski ${ }^{1,2}$, Ewa Wróblewska-Czajka ${ }^{1,2}$, \\ Klaudia Ulfik-Dembska ${ }^{1,2}$ and Edward Wylęgała ${ }^{1,2}$
}

\begin{abstract}
Background: Corneal dystrophies are a group of rare, inherited disorders that are usually bilateral, symmetric, slowly progressive, and not related to environmental or systemic factors. The majority of publications present the advanced form of the disease with a typical clinical demonstration. The initial signs and symptoms of different epithelial and stromal corneal dystrophies are not specific; therefore, it is very important to establish the early characteristic corneal features of these disorders that could guide the diagnostic process.

Case presentation: The main purpose of this study was to report the differential diagnosis of a pediatric patient with bilateral anterior corneal involvement suspected of corneal dystrophy. An 8-year-old male patient presented with asymptomatic, persistent, superficial, bilateral, diffuse, anterior corneal opacities. Slit lamp examination results were not specific. Despite the lack of visible stromal involvement on the slit lamp examination, corneal analysis based on confocal microscopy and optical coherence tomography revealed characteristic features of macular corneal dystrophy (MCD). The diagnosis of MCD was confirmed by CHST6 gene sequencing. The early corneal characteristic features of MCD, established based on the findings of this case report, include corneal astigmatism (not specific), diffuse corneal thinning without a pattern of corneal ectasia (specific), and characteristic features on confocal microscopy (specific), including multiple, dark, oriented striae at different corneal depths.
\end{abstract}

Conclusions: The clinical examination should be complemented with corneal imaging techniques, such as confocal microscopy and optical coherence tomography. In patients suspected of corneal dystrophy, genetic testing plays an important role in establishing the final diagnosis.

Keywords: Macular corneal dystrophy, Confocal microscopy, Optical coherence tomography, CHST6, Corneal dystrophy, Cornea

\footnotetext{
* Correspondence: anna.nowinska@sum.edu.pl

${ }^{1}$ Chair and Clinical Department of Ophthalmology, Faculty of Medical

Sciences in Zabrze, Medical University of Silesia in Katowice, ul. Panewnicka

65, 40-760 Katowice, Poland

${ }^{2}$ Ophthalmology Department, Railway Hospital in Katowice, Katowice, Poland
}

(c) The Author(s). 2021 Open Access This article is licensed under a Creative Commons Attribution 4.0 International License, which permits use, sharing, adaptation, distribution and reproduction in any medium or format, as long as you give appropriate credit to the original author(s) and the source, provide a link to the Creative Commons licence, and indicate if changes were made. The images or other third party material in this article are included in the article's Creative Commons licence, unless indicated otherwise in a credit line to the material. If material is not included in the article's Creative Commons licence and your intended use is not permitted by statutory regulation or exceeds the permitted use, you will need to obtain permission directly from the copyright holder. To view a copy of this licence, visit http://creativecommons.org/licenses/by/4.0/ The Creative Commons Public Domain Dedication waiver (http://creativecommons.org/publicdomain/zero/1.0/) applies to the data made available in this article, unless otherwise stated in a credit line to the data. 


\section{Background}

Macular corneal dystrophy (MCD; OMIM \#217,800; ORPHA98969) is a stromal corneal dystrophy indicated as category 1 according to the International Committee for Classification of Corneal Dystrophies (IC3D) (Category 1: A well-defined corneal dystrophy in which the gene has been mapped and identified and specific mutations are known) [1]. The first symptoms of the disease are usually reported in the second and third decade of life and include gradually deteriorating vision, photophobia, tearing and, rarely, recurrent epithelial erosions $[2,3]$.

The majority of publications and ophthalmic atlases present the advanced form of the disease with a typical clinical demonstration of diffuse, stromal haze and graywhite corneal opacities involving the entire corneal stroma from limbus to limbus; therefore, the diagnosis of dystrophy in the early stages could be challenging. Moreover, diversity in the clinical presentation of MCD has been reported in recent years. Patients with predominantly deep stromal lesions in the peripheral cornea or isolated Descemet membrane deposits have been reported, and the diversity of presentations was confirmed in an optical coherence tomography study [4-6]. Additionally, the disease is of an autosomal recessive origin, expressed only in individuals homozygous for a mutation, which usually causes the diagnosed patient to become the first one affected in the family. In contrast, autosomal dominant corneal dystrophies, such as epithelial-stromal transforming growth factor beta-induced (TGFBI) corneal dystrophies, usually affect many family members, which facilitates the diagnosis of a child from a family with a known diagnosis.

MCD is characterized by a low prevalence. It is estimated that as an indicator, MCD accounts for less than $1 \%$ of keratoplasties according to the Australian Corneal Graft Registry (ACGR) and to the Eye Bank Association of America (EBAA) [7, 8]. In the USA, the prevalence of MCD was calculated as 9.7 per million individuals [9]. While MCD is relatively rare in the United States, it is reported to be most prevalent in Iceland, India and Saudi Arabia [10-12]. Despite its rarity, among stromal dystrophies, MCD is described as the most common [911]. Nevertheless, due to the generally rare prevalence of stromal dystrophies, the differential diagnosis of MCD may be challenging, especially in the early stages of the disease.

The main pathogenetic factor of MCD is the progressive intra- and extracellular accumulation of glycosaminoglycans in stromal keratocytes, Descemet membranes and endothelial cells, leading to the loss of transparency in the corneas of affected patients [1-3, 13]. Mutations in the carbohydrate sulfotransferase gene (CHST6), encoding corneal $\mathrm{N}$-acetylglucosamine-6-sulfotransferase
(C-GlcNac6ST), have been linked to MCD and further reported in patients originating from populations of different regions throughout the world. There is mutational heterogeneity and the predominance of missense mutations, accounting for approximately $50 \%$ of MCD cases) whereas nonsense mutations, deletions, insertions or indels account for approximately $30 \%$ of MCD cases [3, 14-16].

Historically, the confirmation of the diagnosis of MCD was based on the presence of basophilic granular material, which stains positively with periodic acid Schiff, Alcian blue, metachromatic dyes and colloidal iron intra- and extracellularly within the corneal stroma, Descemet membrane and endothelial cells [1]. The broad introduction of noninvasive corneal imaging techniques, including confocal microscopy and anterior segment optical coherence tomography (AS OCT), has revolutionized the diagnosis process and has had a great impact on understanding the pathophysiology of corneal dystrophies.

Confocal microscopy is widely used for analyzing the in vivo microscopic structure in several clinical conditions, such as infectious keratitis, dry eye syndrome, corneal dystrophies and degenerations [17, 18]. Characteristic features of advanced MCD, which have been described and connected to structural and histopathologic data, include hyperreflective areas of basal epithelial cells, rectilinear hyperreflective areas in the anterior stroma, a specific granular appearance to keratocytes and the extracellular matrix accompanied by dark striae of different lengths and orientations, and polymegethism of the corneal endothelial cells containing bright granules in their cytoplasm $[19,20]$.

AS OCT enables in vivo cornea and other anterior chamber structure imaging with an axial resolution from $18 \mu \mathrm{m}$ with time domain OCT (TD OCT) and $5.0 \mu \mathrm{m}$ with spectral domain OCT (SD OCT) to 2,0 $\mu \mathrm{m}$ with high definition OCT (HD OCT). The main pathological features of advanced MCD described in previous studies include general increased reflectivity throughout the corneal stroma, irregularity of the anterior stromal border from the epithelium side, diffuse areas of hyperreflectivity in Bowman's layer caused by corneal deposits and a noticeable layer of increased reflectivity in the posterior, peripheral corneal part [5, 20-22].

For patients with a suspicion of corneal dystrophy, the diagnostic flow includes a detailed familial history, the onset and characterization of signs and symptoms as revealed on the slit lamp exam, and corneal morphology and topography analysis using an available imaging system, such as optical coherence tomography, Scheimflug imaging, Orbscan or confocal microscopy. Finally, molecular diagnosis is becoming increasingly important for establishing the correct diagnosis in challenging cases, as 
is the development of novel genotype-specific treatments.

Considering the challenges in corneal dystrophy differential diagnosis, especially in pediatric populations, we would like to report a pediatric case of macular corneal dystrophy in which the final diagnosis was established based on detailed corneal imaging data confirmed by genetic testing. The case report is part of a study approved by the Ethics Committee of the Medical University of Silesia, Katowice, Poland (KNE/0022/KB1/43/I/ $14 ; 01.07 .2014)$. The patients' parents signed an informed consent form before any study procedure.

\section{Case presentation}

An 8-year-old male patient was referred to the Chair and Clinical Department of Ophthalmology, School of Medicine with the Division of Dentistry in Zabrze, Medical University of Silesia in Katowice by a general ophthalmologist due to persistent, superficial corneal opacities revealed when diagnosed with the mild conjunctivitis two months earlier. The conjunctivitis was treated with ofloxacin eye drops $(3 \mathrm{mg} / \mathrm{ml})$ four times daily and resolved after one week. No specific testing, such as cell culture, immune assays or polymerase chain reaction (PCR), was performed at the acute stage of the conjunctivitis. Due to the persistent superficial corneal abnormalities in both eyes and a suspected diagnosis of multiple subepithelial corneal infiltrates (MSIs) caused by epidemic keratoconjunctivitis (EKC), the patient was administered hydrocortisone eye drops $(3.35 \mathrm{mg} / \mathrm{ml})$ twice daily for two weeks and once daily for one week. There was no significant difference in corneal status; therefore, the patient was referred to our clinic. On examination, he reported no ocular complaints. He had no significant medical or drug history, as well as no previous ocular disease in either eye, except for the reported conjunctivitis. The patient did not have a relevant family history.

The best corrected visual acuity (BCVA) was right eye (RE) $\left(\mathrm{cc}+6.0 \mathrm{Dsph}-4.5\right.$ Dcyl axis $\left.170^{\circ}\right)$ 1.0; left eye (LE) $\left(\mathrm{cc}+6.0 \mathrm{Dsph}-3.5\right.$ Dcyl axis $\left.175^{\circ}\right)$ 1.0. The ocular refraction after tropicamide cycloplegia (1\% tropicamide eye drops administered 3 times every $15 \mathrm{~min}$ ) was RE, + 7.0 Dsph - 4.75 Dcyl axis $170^{\circ}$; LE, + 7.0 Dsph - 4.0 Dcyl axis $175^{\circ}$. The intraocular pressure (IOP) in both eyes was $14 \mathrm{mmHg}$. The axial length was $20.94 \mathrm{~mm}$ for the right eye and $21.12 \mathrm{~mm}$ for the left eye as measured by an IOL Master (Carl Zeiss Meditec, Inc., Dublin, California, USA). On slit lamp examination, multiple diffuse, grayish, indistinct, superficial corneal opacities extending from limbus to limbus accompanied by subepithelial haze were present. The severity of the corneal changes was comparable between eyes (Fig. 1). Fundus examination was unremarkable.

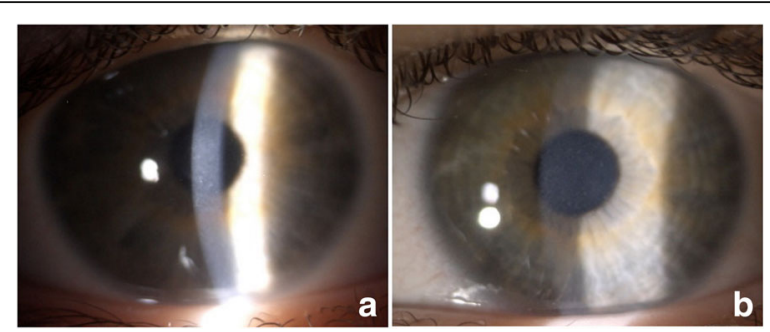

Fig. 1 Representative slit-lamp photographs (SL 9900, Haag-Streit type, CSO, Italy; magnification 10x) of the right eye (a) and left eye (b). Multiple, diffuse, grayish, indistinct, superficial corneal opacities accompanied by subepithelial haze are visible. The severity of the corneal changes was comparable between the eyes

Anterior segment swept source OCT (SS OCT; OCT CASIA2; Tomey, Nagoya, Japan) revealed abnormalities regarding the anterior topography and pachymetry map, as did select parameters from Fourier indices analysis. The pachymetry map revealed bilateral, general corneal thinning. The corneal apical thickness (CAT) of the right eye was $360 \mu \mathrm{m}$, and that of the left eye was $365 \mu \mathrm{m}$. The thinnest portions of the cornea were 352 and $350 \mu \mathrm{m}$ thick, respectively. The location of the thinnest corneal point was the inferotemporal region in both eyes. Keratometric and posterior topography maps confirmed the presence of with-the-rule astigmatism ( $R E=$ 5,3 D; $\mathrm{LE}=4,7 \mathrm{D})$. The corneal shape was characterized as prolate, both for the anterior and posterior surfaces (the anterior and posterior eccentricity of the corneal curve (Ecc) within $9.0 \mathrm{~mm}$ was 0.54 and 0.5 in the RE and 0.51 and 0.4 in the LE, respectively). Anterior and posterior elevation maps showed a typical pattern in which the apex demonstrated warm colors above the BFS (RE: $7 \mu \mathrm{m}, 5 \mu \mathrm{m}$; LE: $9 \mu \mathrm{m}, 4 \mu \mathrm{m}$, respectively) with a slightly elevated isthmus that joined the central cornea from the temporal periphery. Right-left mirror symmetry was present. Three and six millimeter Fourier indices analysis revealed abnormalities regarding two parameters: regular astigmatism on the anterior and posterior surfaces and asymmetry on the anterior surface. The results of $6 \mathrm{~mm}$ keratometric and real higher-order index analysis were borderline in both eyes. The Ectasia Screening Index (ESI), which is a parameter used in the detection of corneas with ectasia patterns implemented in SS OCT software, was $0 \%$ in both eyes. The results of the above anterior and posterior corneal surface analyses and the pachymetry map are presented in Fig. 2. High definition (HD) morphology scans of both eyes revealed very discrete, diffuse hyperreflective opacities with no clearly distinguishable borders and various shapes. Deposits were located in the anterior cornea, just beneath the epithelium (Fig. 3).

A Heidelberg Retina Tomograph 3 Rostock Cornea Module (Heidelberg Engineering $\mathrm{GmbH}$, Dossenheim, 

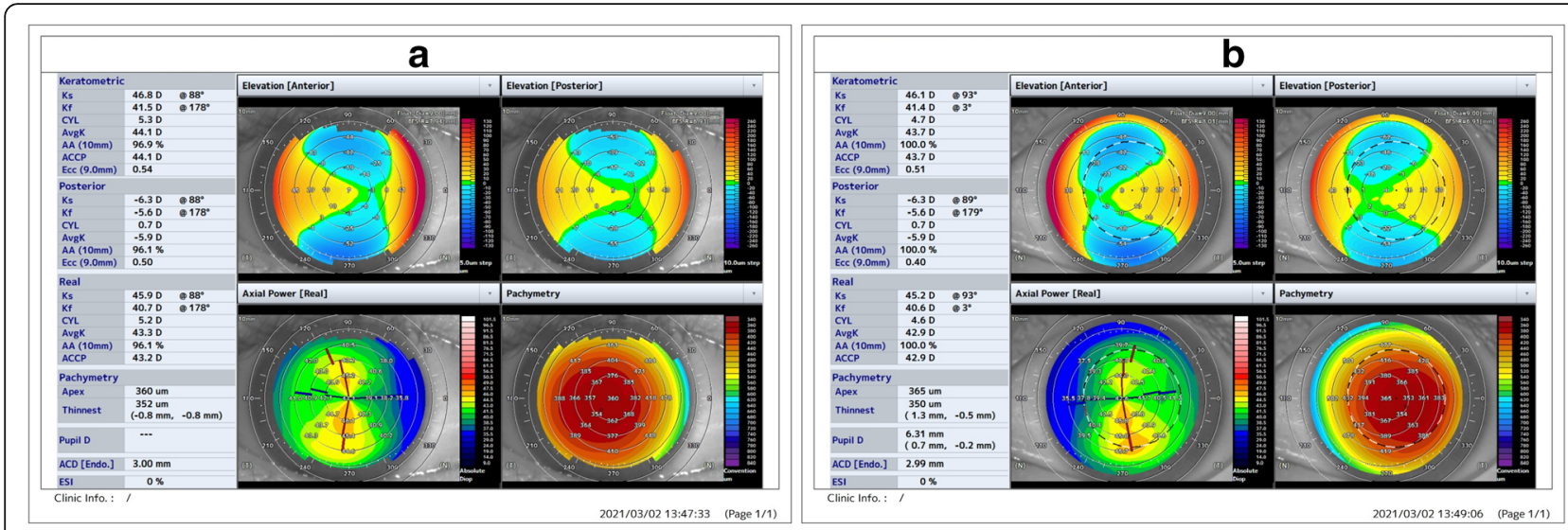

Fig. 2 Swept source OCT (SS OCT) corneal map mode results (16 radial B-scans with 800 A scans per line sampling, total scan duration 0.3 s, diameter $16 \mathrm{~mm}$, and scan depth $11 \mathrm{~mm}$ ) showing the summary of the keratometric, posterior and real keratometry data. Elevation anterior and posterior, real axial power and pachymetry maps of (a) the right eye and (b) the left eye.Pachymetry map revealed bilateral, general corneal thinning. The location of the thinnest corneal point was the inferotemporal region in both eyes. The keratometric map confirms the presence of with-the-rule astigmatism. The corneal shape was characterized as prolate, both of the anterior and posterior surfaces. Anterior and posterior elevation maps showed a typical pattern in which the apex demonstrated warm colors above the best fit sphere (BFS) (RE: $7 \mu$ m, $5 \mu$ m; LE: 9 um, $4 \mu \mathrm{m}$, respectively) with a slightly elevated isthmus that joined the central cornea from the temporal periphery. Right-left mirror symmetry was present. The Ectasia Screening Index (ESI), which is a parameter used in the detection of corneas with ectasia patterns implemented in SS OCT software, was $0 \%$ in both eyes

Germany) was used for the in vivo assessment of the detailed corneal morphology after topical instillation of $0.5 \%$ proparacaine hydrochloride (Alcaine, Alcon Laboratories, Fort Worth, TX, USA) eye drops. The epithelial layers were of normal morphology. Starting at the level of Bowman's layer, multiple, differently oriented dark striae were visible. The morphology of the striae changed at different corneal depths. The striae were especially prominent, multilayered, dark and thick at depths of $90-150 \mu \mathrm{m}$, becoming less evident at increasing depths. The keratocytes and the intercellular space had a granular, hyperreflective appearance throughout the whole stroma. The corneal endothelial morphology was not documented due to poor cooperation of the child during this invasive, uncomfortable examination. The results of confocal microscopy are presented in

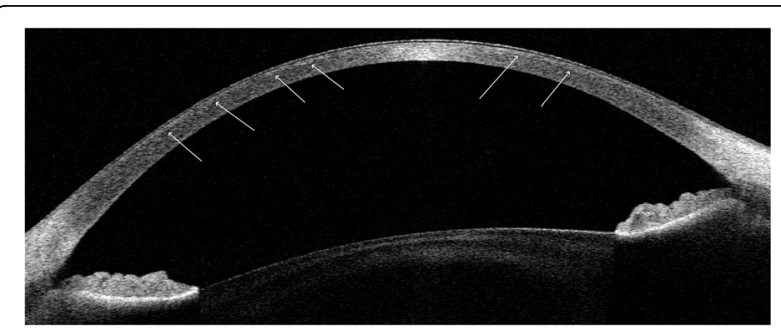

Fig. 3 High-definition morphology SS OCT scan. Very discrete, diffuse, superficial hyperreflective opacities with no clearly distinguishable borders and various shapes are visible. Deposits were located in the anterior cornea, just beneath the epithelium (arrows)
Fig. 4. In contrast to the slit lamp and OCT examination results, where the pathological changes were localized to the superficial layers of the cornea, confocal microscopy revealed changes affecting the whole corneal stroma.

Based on the corneal morphology examination, a suspected diagnosis of stromal corneal dystrophy was made. The majority of corneal dystrophies are characterized by familial occurrence; therefore, the parents were carefully examined to identify possible corneal abnormalities. The examination did not reveal any changes. The familial history also did not reveal any significant ocular diseases or parental consanguinity. Accordingly, a diagnosis of autosomal recessive stromal corneal dystrophy, mainly macular corneal dystrophy, was suspected. The patient could also potentially be the first affected member of the family in case the corneal dystrophy is autosomal dominant.

To establish the final diagnosis, next-generation sequencing was incorporated. Blood samples were collected from the patient and patient's parents after obtaining written informed consent for genetic testing of the coding regions of the following genes linked with corneal dystrophies: CHST6, TGFBI, KRT3, KRT12, COL8A2, SLC4A11, TACSTD2, UBIAD1, VSX1, and $Z E B 1$. The next-generation sequencing (NGS) technique was performed with the SeqCap EZ Hyper Cap protocol and a NimbleGen SeqCap EZ probe kit (Roche Sequencing Solutions, Inc; CA; USA) using a NextSeq sequencer by Illumina (Illumina, San Diego, CA, USA). NGS analyses with a mean read coverage of at least $40 \times$ were 

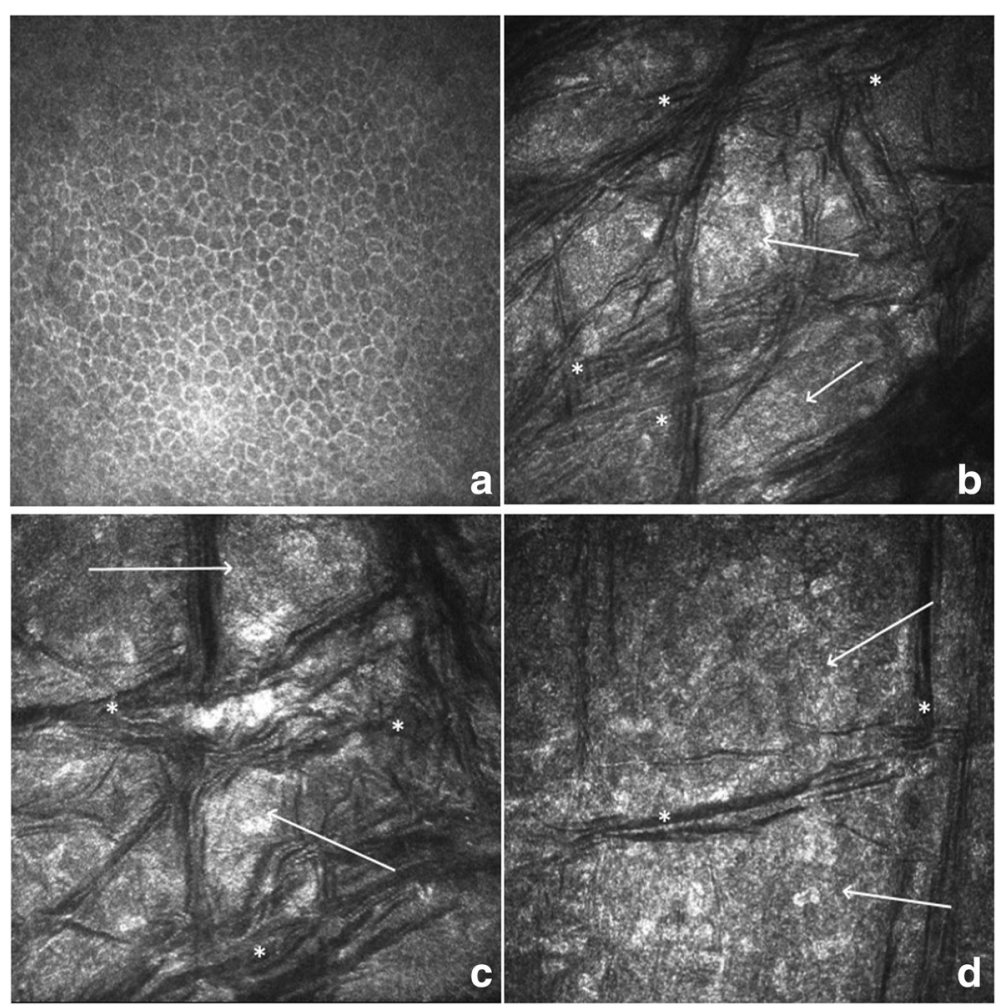

Fig. 4 Representative confocal microscopy images at different scanning depths. (a) Confocal image at a depth of $10 \mu \mathrm{m}$. No significant abnormalities in the corneal epithelium were visible. (b) Confocal image at a depth of $80 \mu \mathrm{m}$. (c) Confocal image at a depth of $120 \mu \mathrm{m}$. (d) Confocal image at a depth of $330 \mu \mathrm{m}$. Granular, hyperreflective appearance of the corneal stroma (arrows) with multiple, differently oriented dark striae $\left(^{*}\right)$. The striae were especially prominent, multilayered, dark and thick at depths from 90-150 $\mu \mathrm{m}(\mathbf{b}$, c), becoming less evident at increasing depths (d)

considered successful. The test result was confirmed using the Sanger reference method, described in detail in our previous publication [20]. All mutations were described according to the Human Genome Variation Society nomenclature (HGVSv19.01). For the analysis of the CHST6 gene, the reference sequence with accession number NM_021615.4 (HGMD Professional 2019.4) was used. The known homozygous, pathogenic variant c.1 A > T (p.M1?) was found following CHST6 gene analysis for our patient (proband). CHST6 gene sequencing for both parents revealed the same variant in a heterozygous state (Fig. 5).

Based on the results of the corneal morphology analysis combined with the genetic testing results, the diagnosis of macular corneal dystrophy was made. The patient was referred to the corneal outpatient clinic for further control visits.

\section{Discussion and csonclusions}

Corneal dystrophies, according to the IC3D classification system are categorized into epithelial and subepithelial, epithelial-stromal TGFBI, and stromal and endothelial dystrophies [1]. The overall classification includes 22 different types of corneal dystrophies, frequently further divided into subcategories. The differential diagnosis of corneal dystrophies is challenging and includes infectious corneal diseases, mostly of the viral form, corneal degenerations, such as mosaic (crocodile shagreen) degeneration, cornea farinata or peripheral hypertrophy, subepithelial corneal degeneration, vernal keratoconjunctivitis, and keratopathies related to dry eye disease, such as keratoconjunctivitis sicca or keratopathies related to blepharitis. Additionally, corneal diseases of unknown origin, such as Thygeson's superficial punctate keratitis (TSPK), or of various systemic causes, including several skin diseases, monoclonal gammopathy, enzymerelated deficiencies (tyrosinemia, lecithin-cholesterolacyltransferase deficiency, mucopolysaccharidoses), systemic lysosomal storage diseases or cystinosis, should be incorporated into the differential diagnosis.

After the initial interview and slit lamp examination of our patient, which revealed multiple, diffuse, grayish, indistinct, superficial corneal opacities extending from limbus to limbus, accompanied by subepithelial haze (Fig. 1), the most likely differential diagnoses included epithelial, subepithelial or stromal corneal dystrophy, 


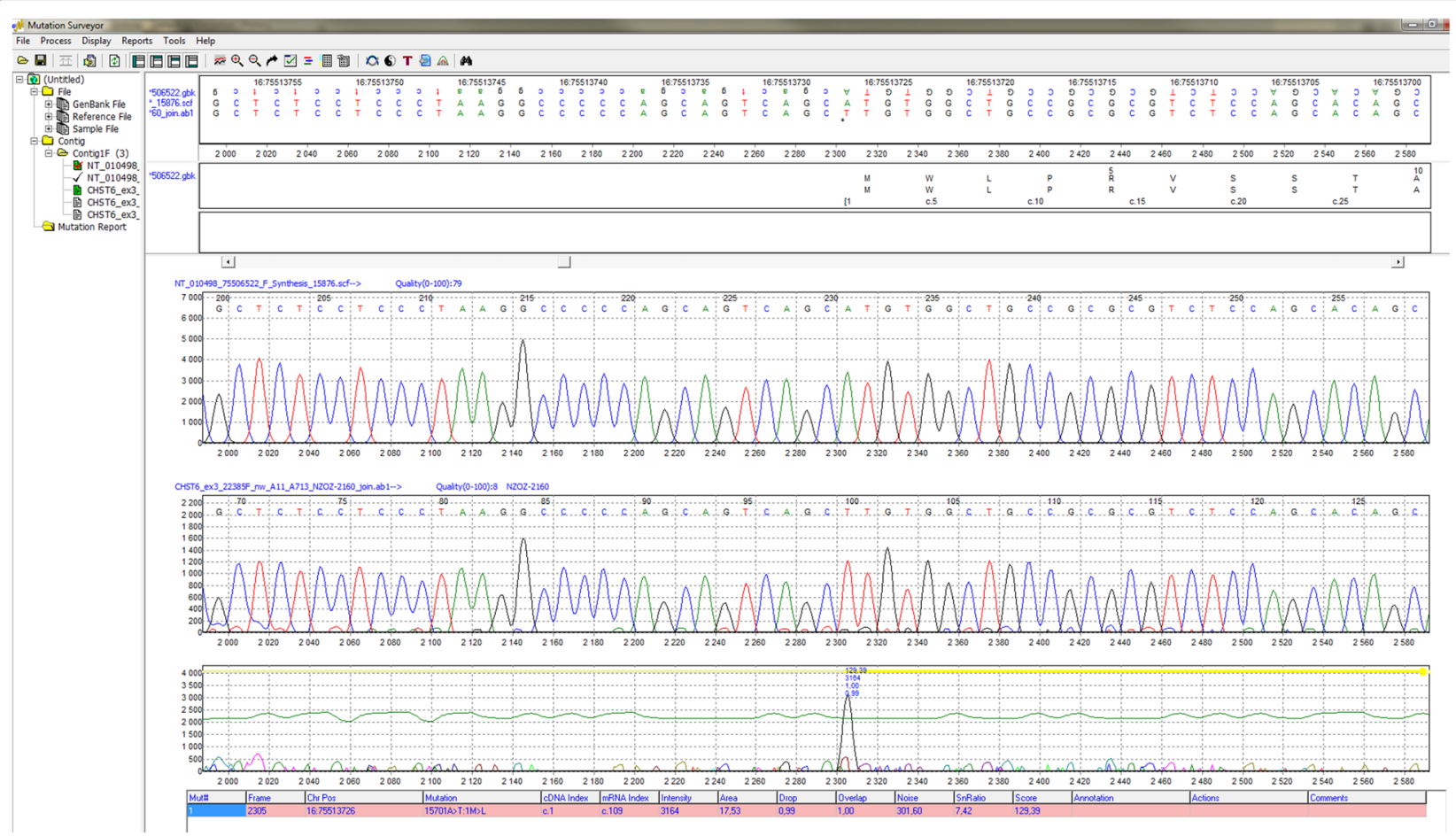

Fig. 5 Graphic presentation of the homozygous pathogenic variant c.1 A > T (p.M1?) of the CHST6 gene

multiple subepithelial corneal infiltrates caused by epidemic keratoconjunctivitis or Thygeson's superficial punctate keratitis (TSPK). The majority of epithelial and epithelial-stromal TGFBI corneal dystrophies are autosomal dominant, but the patient could have been the first affected member of the family. Moreover, the early signs of stromal dystrophies include epithelial and subepithelial corneal abnormalities, subsequently followed by stromal involvement; therefore, stromal dystrophies could not be ruled out only because slit lamp examination did not reveal stromal involvement and due to the young age of the patient.

Multiple subepithelial corneal infiltrates may be caused by epidemic keratoconjunctivitis, they usually occur during the subacute and chronic phases and may persist for months to years. In the slit lamp examination, the probability of central corneal involvement, namely, involvement of the pupillary zone, is higher than that of peripheral corneal involvement. This was not consistent with our patient's results, since the corneal changes were diffuse rather than centralized. On confocal microscopy, MSIs are visible as distinct round hyperreflective plaques, accompanied by increased anterior stromal hyperreflectivity and hyperreflective foci and inflammatory cells within the basal epithelium $[23,24]$.

Based on the corneal appearance on slit lamp examination, TSPK should also be considered in the differential diagnosis. TSPK is a bilateral corneal disease of unknown origin in which factors such as viral infection or the immune reaction to viral infection and allergic reactions have been proposed to play a pathogenic role. Slit lamp examination reveals numerous punctate opacities involving the epithelium and underlining superficial corneal stroma. Confocal microscopy changes are characteristic and include highly reflective deposits with a starburst-like appearance in the superficial and basal epithelial cell layers, an increased number of dendritic cells in the epithelial basal cell layer and the subepithelial nerve plexus, and highly reflective, tiny, needle-shaped material in the anterior corneal stroma [25, 26].

In contrast to MSIs and TSPK features, confocal microscopy analysis for our patient revealed significant stromal involvement. Starting at the level of Bowman's layer, multiple, differently oriented dark striae were visible. The keratocytes and the intercellular space had a granular, hyperreflective appearance throughout the whole stroma (Fig. 4). These findings are consistent with previous reports describing confocal corneal changes in MCD. In contrast to those at advanced stages, the epithelium layers of our patient were of normal morphology, while in advanced forms, numerous hyperreflective basal epithelial cells among cells of normal morphology were reported $[19,20]$. Despite the lack of visible stromal involvement on slit lamp examination, 
the cornea presented changes involving the deep stromal layers, confirming the high utility of confocal microscopy in the differential diagnosis of corneal dystrophies.

Clinical examination of our patient also showed regular corneal astigmatism and diffuse corneal thinning, which are characteristic features of MCD, confirmed by previous histopathological, Scheimpflug imaging, ultrasound biomicroscopy and OCT studies [5, 20, 27-30]. The diffuse corneal thinning is believed to be a result of the dysregulation of keratan sulfate proteoglycan synthesis or catabolism, which directly influences corneal structure [31]. The above observation leads us to conclude that generalized corneal thinning precedes the progressive loss of corneal transparency. A highdefinition corneal scan of our patient revealed very discrete, diffuse hyperreflective opacities with no clearly distinguishable borders and various shapes located in the subepithelial regions. As the disease progresses, OCT scans show hyperreflective stromal corneal deposits with associated thinning of the epithelium over the deposits and characteristic pre-Descemetic peripheral deposits. In some patients, thickening of the Descemet membrane may be noted. In advanced stages of the dystrophy, dense stromal deposits cause an optical shadow in the posterior part of the cornea. Additionally, the progression of deposits in the endothelial cell layer can eventually lead to endothelial decompensation and increased corneal thickness [1, 4, 5, 20-22, 28].

It has been described that the visual function of patients with corneal dystrophies is not only compromised by scattering induced by the corneal opacity but also associated and correlated with higher-order aberrations (HOAs). HOAs of the total cornea and anterior and posterior surfaces were reported to be larger in subjects with stromal corneal dystrophies than in normal control subjects [32, 33]. The analysis of the Fourier indices for our patient revealed abnormalities regarding two parameters: regular astigmatism on the anterior and posterior surfaces and asymmetry on the anterior surface. The results of the $6 \mathrm{~mm}$ keratometric and real higher order index analyses were borderline in both eyes, while the results of the $3 \mathrm{~mm}$ and $6 \mathrm{~mm}$ posterior higher-order index analyses were within the normal range. YagiYaguchi Y. et al. reported that HOAs were increased at the late stage of MCD. Their study group compromised 13 eyes of seven patients with advanced MCD without genetic confirmation; the mean age of the patients was $49.9 \pm 5.8$ years, and the visual acuity was $\log$ MAR $0.48 \pm 0.62$ [32]. The results cannot be compared directly to our results because of the significant difference in age and visual acuity (our patient's age was 8 years, and VA was $\log$ MAR 0.0). Age has been reported to be strongly correlated with visual function, refraction, astigmatism and HOAs [34]. The borderline results of the $6 \mathrm{~mm}$ higher-order keratometric index in our patient may be directly connected to the anterior subepithelial abnormalities revealed by HD OCT scans and may indicate that Fourier index abnormalities occur early in the disease course. On the other hand, such subtle changes on the anterior surface of the cornea are not specific, and the result may be influenced by several factors, such as disturbances of the tear film, patient cooperation during the examination or internal/indoor environmental factors $[35,36]$. Therefore, the influence of MCD on Fourier index results should be studied in a larger sample size, and one case report cannot be representative of the population.

There are few case reports on the cooccurrence of keratoconus and MCD [37, 38]. In the study of Dudakova et al., the authors observed anterior, paracentral steepening of the corneal surface, which was graded as keratoconus by Scheimflug integrated software, but without a coexisting ectasia pattern on the posterior corneal surface [28]. The anterior and posterior Ectasia Screening Index (ESI), which is a parameter used in the detection of corneas with ectasia patterns implemented in the SS OCT software, was $0 \%$ in both eyes of our patient. Thus, our findings may serve as evidence of diffuse corneal thinning not associated with an ectasia pattern.

According to the American Society of Ophthalmology guidelines, genetic testing should be offered to patients with clinical findings suggestive of a Mendelian disorder, whose causative gene(s) have been identified [39, 40]. The known, previously described homozygous pathogenic variant, c.1 A $>\mathrm{T}$, with alteration of the start codon (p.M1?) was found following CHST6 gene sequencing in our patient, thus confirming a diagnosis of MCD. Alterations of the first codon have also been reported in Polish, Czech, German and Turkish populations [20, 41-43]. It is wort mentioning, that in case of MCD, not only missense mutations are pathogenic, but also deletions, insertions or indels, which account for approximately $30 \%$ of MCD cases. In our case, the upstream region of the CHST6 gene was not covered by the gene sequencing, which could be regarded as a study limitation. Genetic testing provides future prospects for implementing gene therapy. Moreover, MCD with precisely identified genetic defects fulfils the prerequisites for attempting clinical gene therapy [44]. Currently, we are faced with new possibilities in future methods of gene therapy, such as clustered regularly interspaced short palindromic DNA repeat (CRISPR) and CRISPRassociated gene (cas) systems of gene editing. Such an approach was already employed in Meesman corneal dystrophy [44-46].

The main importance of this case report is in defining the early characteristic features of MCD, despite the absence of characteristic corneal abnormalities on slit lamp 
examination. The main limitations are the difficulties in performing high-quality slit lamp and confocal microscopy scans in an 8-year-old patient. Additionally, the influence of environmental factors and tear film disturbances could interfere with the OCT Fourier indices results.

To conclude, the initial signs and symptoms of different epithelial and stromal corneal dystrophies are not specific; therefore, it is very important to establish early characteristic corneal features that could guide the diagnostic process. The clinical examination should be complemented with corneal imaging techniques, such as confocal microscopy and optical coherence tomography. Early corneal characteristic features of MCD, established according to the findings of the case report, include corneal astigmatism (not specific), diffuse corneal thinning without a pattern of corneal ectasia (specific), and those obtained on confocal microscopy (specific), including multiple, dark, oriented striae at different corneal depths. In patients suspected of corneal dystrophy, genetic testing plays an important role in establishing the final diagnosis and may provide encouraging results for future gene therapy.

\section{Abbreviations}

ACGR: Australian Corneal Graft Registry; AS OCT: Anterior segment optical coherence tomography; BCVA: Best corrected visual acuity; CAT: Corneal apical thickness; Cas: Clustered regularly interspaced short palindromic DNA repeat-associated genes; cc: With refractive correction; C-GlcNac6ST: Corneal $\mathrm{N}$-acetylglucosamine-6-sulfotransferase; CHST6: Carbohydrate sulfotransferase; COL8A2: Collagen Type VIII Alpha 2 Chain; cyl: Cylinder; CRISPR: Clustered regularly interspaced short palindromic DNA repeat; D: Diopter; EBAA: Eye Bank Association of America; EBMD: Epithelial basement membrane dystrophy; EKC: Epidemic keratoconjunctivitis; EREDs: Epithelial recurrent erosion dystrophies; ESI: Ectasia Screening Index; GCD: Granular corneal dystrophy; HD OCT: High definition OCT; HOAs: Higher order aberrations; IC3D: International Committee for Classification of Corneal Dystrophies; IOP: Intraocular pressure; KRT3: Keratin 3; KRT12: Keratin 12; LE: Left eye; MCD: Macular corneal dystrophy; MECD: Meesmann corneal dystrophy; MSIs: Multiple subepithelial corneal infiltrates; NGS: Next generation sequencing; PCR: Polymerase chain reaction; RE: Right eye; SD OCT: Spectral domain OCT; SLC4A11: Solute Carrier Family 4 Member 11;

SMCD: Subepithelial mucinous corneal dystrophy; Sph: Spherical; SS OCT: Swept source OCT; TACSTD2: Tumor Associated Calcium Signal Transducer 2; TD OCT: Time domain OCT; TGFBI: Transforming growth factor beta-induced; TSPK: Thygeson's superficial punctate keratitis; UBIAD1: UbiA Prenyltransferase Domain Containing 1; VSX1: Visual System Homeobox 1; ZEB1: Zinc Finger E-Box Binding Homeobox 1

\section{Acknowledgements}

none.

\section{Authors' contributions}

AN was a major contributor to conducting the research plan and preparing the manuscript. MD was responsible for performing confocal microscopy exam and analysis of the results. ECHT was responsible for performing optical coherence tomography exams and analysis of the results. AN analyzed and interpreted the patient's ophthalmologic and genetic data. EWCZ, KUD and EW reviewed and edited the manuscript. All named authors take responsibility for the integrity of the work as a whole and have given their approval for this version to be published.

\section{Funding}

This research was supported by Polish National Science Centre grant SONATA-8, contract number 2014/15/D/NZ5/03404. "Phenotype-genotype analysis of patients with corneal dystrophies originating from Polish population". Pl - Anna Nowińska.

\section{Availability of data and materials}

All data generated or analyzed during this study are included in this published article.

\section{Declarations}

Ethics approval and consent to participate

The study was approved by the Ethics Committee of the Medical University of Silesia, Katowice, Poland (KNE/0022/KB1/43///14; 01.07.2014). The patients' parents signed an informed consent form before any study procedure.

\section{Consent for publication}

Written consent for publication of this case report was obtained from patient's parents.

\section{Competing interests}

All authors have no competing interests.

Received: 15 March 2021 Accepted: 7 July 2021

Published online: 23 July 2021

\section{References}

1. Weiss JS, Møller HU, Aldave AJ, Seitz B, Bredrup C, Kivelä T, et al. IC3D classification of corneal dystrophies-edition 2. Cornea. 2015;34:117-59. doi: https://doi.org/10.1097//CO.0000000000000307.

2. Aggarwal S, Peck T, Golen J, Karcioglu ZA. Macular corneal dystrophy: A review. Surv Ophthalmol. 2018;63:609-17. doi:https://doi.org/10.1016/j. survophthal.2018.03.004.

3. Singh S, Das S, Kannabiran C, Jakati S, Chaurasia S. Macular Corneal Dystrophy: An Updated Review. Curr Eye Res. 2020;29:1-6. doi:https://doi. org/10.1080/02713683.2020.1849727.

4. Zhang W, Kassels AC, Barrington A, Khan S, Tomatsu S, Alkadi T, et al. Macular corneal dystrophy with isolated peripheral Descemet membrane deposits. Am J Ophthalmol Case Reports. 2019;16:100571. doi:https://doi. org/10.1016/j.ajoc.2019.100571.

5. Chaurasia S, Ramappa M, Mishra DK. Clinical diversity in macular corneal dystrophy: an optical coherence tomography study. Int Ophthalmol. 2019; 39:2883-8. doi:https://doi.org/10.1007/s10792-019-01136-2.

6. Chaurasia S, Mishra DK. Atypical presentation of macular corneal dystrophy managed by Descemet stripping endothelial keratoplasty. Indian J Ophthalmol. 2019;67:118-9. doi:https://doi.org/10.4103/jjo.IJO_602_18.

7. Williams K, Anne, Keane M, Claire, Coffey N, Elizabeth, Jones VJ, Mills RA, Coster DJ. The Australian Corneal Graft Registry. 2018. https://nla.gov.au/nla. obj-726934474/view.

8. Eye Bank Association of America. Eye Banking Statistical Report. 2013. 2013. http://restoresight.org/wp-content/uploads/2014/04/2013_Statistical_ReportFINAL.pdf.

9. Musch DC, Niziol LM, Stein JD, Kamyar RM, Sugar A. Prevalence of corneal dystrophies in the United States: Estimates from claims data. Investig Ophthalmol Vis Sci. 2011;52:6959-63. doi:https://doi.org/10.1167/iovs.117771

10. Das AV, Chaurasia S. Clinical Profile and Demographic Distribution of Corneal Dystrophies in India. Cornea. 2020;Publish Ah. https://doi.org/10.1 097/ico.0000000000002450

11. Alzuhairy S, Alkatan HM, Al-Rajhi AA. Prevalence and histopathological characteristics of corneal stromal dystrophies in Saudi Arabia. Middle East Afr J Ophthalmol. 2015:22:179-85.

12. Liu NP, Smith CF, Bowling BL, Jonasson F, Klintworth GK. Macular corneal dystrophy types I and II are caused by distinct mutations in the CHST6 gene in Iceland. Mol Vis. 2006:12:1148-52.

13. Lisch W, Weiss JS. Clinical and genetic update of corneal dystrophies. Exp Eye Res. 2019;186:107715. doi:https://doi.org/10.1016/..exer.2019.107715.

14. Vance JM, Jonasson F, Lennon F, Sarrica J, Damji KF, Stauffer J, PericakVance MAKG. Linkage of a gene for macular corneal dystrophy to chromosome 16. Am J Hum Genet. 1996;58:757-62. 
15. Akama TO, Nishida K, Nakayama J, Watanabe H, Ozaki K, Nakamura T, et al Macular corneal dystrophy type I and type II are caused by distinct mutations in a new sulphotransferase gene. Nat Genet. 2000;26:237-41. doi: https://doi.org/10.1038/79987.

16. Liu NP, Dew-Knight S, Rayner M, Jonasson F, Akama TO, Fukuda MN, et al. Mutations in corneal carbohydrate sulfotransferase 6 gene (CHST6) cause macular corneal dystrophy in Iceland. Mol Vis. 2000;6:261-4.

17. Erie JC, McLaren JW, Patel SV. Confocal Microscopy in Ophthalmology. Am J Ophthalmol. 2009;148:639-46. doi:https://doi.org/10.1016/j.ajo.2009.06.022.

18. Kokot J, Wylęgała A, Wowra B, Wójcik Ł, Dobrowolski D, Wylęgała E. Corneal confocal sub-basal nerve plexus evaluation: a review. Acta Ophthalmol. 2018;96:232-42. doi:https://doi.org/10.1111/aos.13518.

19. Micali A, Pisani A, Puzzolo D, Nowińska A, Wylegala E, Teper S, et al. Macular corneal dystrophy: In vivo confocal and structural data. Ophthalmology. 2014;121:1164-73. doi:https://doi.org/10.1016/j.ophtha.2013.12.012.

20. Nowinska AK, Wylegala E, Teper S, Wróblewska-Czajka E, Aragona P, Roszkowska AM, et al. Phenotype and genotype analysis in patients with macular corneal dystrophy. Br J Ophthalmol. 2014;98:1514-21. doi:https:// doi.org/10.1136/bjophthalmol-2014-305098.

21. Siebelmann S, Scholz P, Sonnenschein S, Bachmann B, Matthaei M, Cursiefen $C$, et al. Anterior segment optical coherence tomography for the diagnosis of corneal dystrophies according to the IC3D classification. Surv Ophthalmol. 2018;63:365-80.

22. Elhardt C, Priglinger SG, Karakolova Y, Mayer WJ, Wertheimer C. Corneal dystrophies in optical coherence tomography. Ophthalmologe. 2019;116: 857-64. doi:https://doi.org/10.1007/s00347-018-0832-8.

23. Subaşı S, Yüksel N, Toprak M, Tuğan BY. In vivo confocal microscopy analysis of the corneal layers in adenoviral epidemic keratoconjunctivitis. Turkish J Ophthalmol. 2018;48:276-80.

24. Hou W, Sun $X$, Feng J, Zhang Y, Wang Z. A 8-year retrospective clinical analysis of 272 patients of epidemic Keratoconjunctivitis in Beijing, China. BMC Ophthalmol. 2019;19:262. doi:https:/doi.org/10.1186/s12886-019-1266-z.

25. Kawamoto K, Chikama TI, Takahashi N, Nishida T. In vivo observation of Langerhans cells by laser confocal microscopy in Thygeson's superficial punctate keratitis. Mol Vis. 2009;15:1456-62.

26. Kobayashi A, Yokogawa $H$, Sugiyama K. In vivo laser confocal microscopy findings of thygeson superficial punctate keratitis. Cornea. 2011;30:675-80.

27. Donnenfeld ED, Cohen EJ, Ingraham HJ, Poleski SA, Goldsmith E, Laibson PR. Corneal thinning in macular corneal dystrophy. Am J Ophthalmol. 1986; 101:112-3. doi:https://doi.org/10.1016/0002-9394(86)90473-3.

28. Dudakova L, Palos M, Svobodova M, Bydzovsky J, Huna L, Jirsova K, et al. Macular corneal dystrophy and associated corneal thinning. Eye. 2014;28: 1201-5. doi:https://doi.org/10.1038/eye.2014.164.

29. Feizi S, Karjou Z, Abbasi H, Javadi MA, Azari AA. Characterization of In Vivo Biomechanical Properties in Macular Corneal Dystrophy. Am J Ophthalmol. 2020;215:8-13.

30. Rubinstein Y, Weiner C, Einan-Lifshitz A, Chetrit N, Shoshany N, Zadok D, et al. Macular corneal dystrophy and posterior corneal abnormalities. Cornea. 2016;35:1605-10. doi:https://doi.org/10.1097/ICO.0000000000001054.

31. Akhtar S, Bron AJ, Hayes AJ, Meek KM, Caterson B. Role of keratan sulphate (sulphated poly - $\mathrm{N}$-acetyllactosamine repeats) in keratoconic cornea, histochemical, and ultrastructural analysis. Graefe's Arch Clin Exp Ophthalmol. 2011;249:413-20. doi:https:/doi.org/10.1007/s00417-010-1512-9.

32. Yagi-Yaguchi $Y$, Yamaguchi T, Okuyama Y, Satake Y, Tsubota K, Shimazaki J. Corneal higher order aberrations in granular, lattice and macular corneal dystrophies. PLoS One. 2016;11:e0161075. doi:https://doi.org/10.1371/journa I.pone.0161075.

33. Kamiya K, Kobashi H, Igarashi A, Shoji N, Shimizu K. Effect of Light Scattering and Higher-order Aberrations on Visual Performance in Eyes with Granular Corneal Dystrophy. Sci Rep. 2016;6:24677. doi:https://doi.org/10.1038/srep24677.

34. Oshika T, Okamoto C, Samejima T, Tokunaga T, Miyata K. Contrast Sensitivity Function and Ocular Higher-Order Wavefront Aberrations in Normal Human Eyes. Ophthalmology. 2006;113:1807-12. doi:https://doi.org/10.1016/j. ophtha.2006.03.061.

35. Chuang J, Shih KC, Chan TC, Wan KH, Jhanji V, Tong L. Preoperative optimization of ocular surface disease before cataract surgery. J Cataract Refract Surg. 2017;43:1596-607.

36. Epitropoulos AT, Matossian C, Berdy GJ, Malhotra RP, Potvin R. Effect of tear osmolarity on repeatability of keratometry for cataract surgery planning. J Cataract Refract Surg. 2015:41:1672-7. doi:https://doi.org/10.1016/j.jcrs.2015. 01.016.
37. Javadi MA, Rafee'l AB, Kamalian N, Karimian F, Ja'farinasab MR, Yazdani S Concomitant keratoconus and macular corneal dystrophy. Cornea. 2004;23: 508-12. doi:https://doi.org/10.1097/01.ico.0000114124.63670.dd.

38. Mohammad-Rabei H, Shojaei A, Aslani M. Concurrent macular corneal dystrophy and keratoconus. Middle East Afr J Ophthalmol. 2012;19:251-3.

39. Verma IC, Paliwal P, Singh K. Genetic Testing in Pediatric Ophthalmology. Indian J Pediatr. 2018;85:228-36. doi:https://doi.org/10.1007/s12098-017-24 53-7.

40. Stone EM, Aldave AJ, Drack AV, MacCumber MW, Sheffield VC, Traboulsi E, et al. Recommendations for genetic testing of inherited eye diseases: Report of the American academy of ophthalmology task force on genetic testing. Ophthalmology. 2012;119:2408-10. doi:https://doi.org/10.1016/j. ophtha.2012.05.047.

41. Liskova P, Veraitch B, Jirsova K, Filipec M, Neuwirth A, Ebenezer ND, et al. Sequencing of the CHST6 gene in Czech macular corneal dystrophy patients supports the evidence of a founder mutation. Br J Ophthalmol. 2008:92:265-7. doi:https://doi.org/10.1136/bjo.2007.125252.

42. Tuncay FY, Kurekci GK, Ergun SG, Pasaoglu OT, Akata RF, Dincer PR. Genetic analysis of CHST6 and TGFBI in Turkish patients with corneal dystrophies: Five novel variations in CHST6. Mol Vis. 2016:22:1267-79.

43. Gruenauer-Kloevekorn C, Braeutigam S, Heinritz W, Froster UG, Duncker GIW. Macular corneal dystrophy: Mutational spectrum in German patients, novel mutations and therapeutic options. Graefe's Arch Clin Exp Ophthalmol. 2008;246:1441-7.

44. Moore CBT, Christie KA, Marshall J, Nesbit MA. Personalised genome editing - The future for corneal dystrophies. Progress in Retinal Eye Research. 2018; 65:147-65. doi:https://doi.org/10.1016/j.preteyeres.2018.01.004

45. Courtney DG, Moore JE, Atkinson SD, Maurizi E, Allen EHA, Pedrioli DML, et al. CRISPR/Cas9 DNA cleavage at SNP-derived PAM enables both in vitro and in vivo KRT12 mutation-specific targeting. Gene Ther. 2016;23:108-12. doi:https://doi.org/10.1038/gt.2015.82

46. Christie KA, Courtney DG, Dedionisio LA, Shern CC, De Majumdar S, Mairs $L C$, et al. Towards personalised allele-specific CRISPR gene editing to treat autosomal dominant disorders. Sci Rep. 2017;7:16174. doi:https://doi.org/1 0.1038/s41598-017-16279-4.

\section{Publisher's Note}

Springer Nature remains neutral with regard to jurisdictional claims in published maps and institutional affiliations.

Ready to submit your research? Choose BMC and benefit from:

- fast, convenient online submission

- thorough peer review by experienced researchers in your field

- rapid publication on acceptance

- support for research data, including large and complex data types

- gold Open Access which fosters wider collaboration and increased citations

- maximum visibility for your research: over $100 \mathrm{M}$ website views per year

At $\mathrm{BMC}$, research is always in progress.

Learn more biomedcentral.com/submission 